\title{
The Influence of Language Contact and Vocabulary Knowledge on the Speaking Performance of Japanese Students of English
}

\author{
Taeko Oya ${ }^{1}$, Emmanuel Manalo*,2 $^{*}$ and Jackie Greenwood ${ }^{1}$ \\ ${ }^{I}$ Department of Applied Language Studies and Linguistics, The University of Auckland, New Zealand \\ ${ }^{2}$ Student Learning Centre, The University of Auckland, New Zealand
}

\begin{abstract}
This study examined the influence of language contact and vocabulary knowledge on the speaking performance of 73 Japanese students in English language schools in New Zealand. The participants completed a language contact profile questionnaire and a vocabulary test, and were administered a story retelling task (which constituted the measure of speaking performance). The results revealed that vocabulary knowledge correlated with fluency, accuracy, complexity, and global impression aspects of speaking performance. Time spent on the following were also found to correlate positively with various aspects of speaking performance: studying English, staying in English-speaking countries, speaking English outside of school, speaking English with non-native English speakers, and reading. In contrast, time spent watching television was found to negatively correlate with speaking accuracy.
\end{abstract}

Keywords: English speaking performance, Japanese students, language contact, vocabulary knowledge.

\section{INTRODUCTION}

Practice in the use of a language that one is studying is generally believed to be essential in developing proficiency. In countries like Japan, where English education is now very important for people of all ages [1], many young people travel and spend time overseas to - among other things seek more opportunities to use the English language skills they are learning in environments where English is the predominant mode of communication. The Institute of International Education [2], for example, reported that during the 2004-2005 academic year, 42,215 Japanese students studied in the US, placing Japan as the fourth largest origin of international students in the US behind India, China, and the Republic of Korea.

Vocabulary development is another factor that is commonly believed to be essential in successfully learning another language. Read [3] observed that many students tend to view language learning as essentially a matter of learning words so they spend a great deal of time on vocabulary acquisition and largely depend on their bilingual dictionary in situations where they are required to communicate in the target language. This view about the importance of vocabulary development held by many students studying another language is shared by many language teachers, researchers, and psycholinguists: Read, for example, stressed the fact that words are the basic components of language, and Levelt [4] considered vocabulary knowledge as the mechanism that drives speech production.

If these assumption about the importance of language contact and vocabulary knowledge in language learning are true, it raises the question of how extensively these factors

*Address correspondence to this author at the Student Learning Centre, The University of Auckland, Private Bag 92019, Auckland 1142, New Zealand; E-mail: e.manalo@auckland.ac.nz might influence a language learner's speaking ability. Very few studies have looked at the effect of language contact outside the classroom and, as far as the present authors are aware, no research has previously been carried out on the relationship between vocabulary knowledge and oral performance of second language learners. Investigating the effects that these factors might have is important as the findings could contribute to better language learning practices: language contact outside the classroom and vocabulary acquisition are both largely within the control of students studying a language, and both are factors that language instructors could provide best practice advise to students about.

\section{The Importance of Language Contact}

Language contact outside the classroom is believed to be important because it can provide "potential practice opportunities" (p. 269) for the second language [5]. This notion is supported by numerous researchers in this area: d'Anglejan [6], for example, claimed that, without the necessary practice, studying a language is not enough to improve second language proficiency. Other authors also insist that to learn to speak, second language learners need opportunities to speak [7, 8]. In addition, the benefits of language contact appears to apply to numerous aspects of language learning: through contact with the language being learnt via pleasure reading, for example, ESL (English as a second language) students have been found to learn grammar and vocabulary, improve their reading, writing, and comprehension skills, as well as develop greater confidence in using English [9, 10].

Despite the apparent importance of language contact to language learning, there are not many research studies that have investigated the relationship between language contact and the oral performance of second language learners. Earlier studies have focused on classroom participation as a measure of oral performance and have obtained mixed re- 
sults: for example, Seliger [5] found evidence of a relationship with language contact, while Day [11] did not. More recently, Freed, Segalowitz, and Dewey [12] found that the time students spent in using the second language (in this case, French) in out-of-class activities was associated with differences in oral fluency gains. However, while Segalowitz and Freed [13] found that students who spent a semester studying Spanish abroad appeared to have some advantages over students who studied in their home university as far as oral performance gains were concerned, they found no evidence to indicate that the gains made by both groups were related to amount of in-class or out-of-class contact with the target language. In fact, for the study abroad students, a significant negative correlation was found between reported time spent speaking with home-stay family and one of the fluency measures employed (length of longest turn).

\section{The Importance of Vocabulary Knowledge}

Most of the previous studies that have looked at the influence of vocabulary knowledge on language learning have focused on its relationship to reading comprehension and academic achievement, but not oral performance. Laufer [14], for example, reported significant correlations between measures of vocabulary knowledge and reading comprehension assessments of first year arts and social science students in an Israeli university. Hazenberg and Hulstijn [15] reported similar results: in a Dutch university, they found that nonnative prospective university students who passed a reading comprehension test (that was administered as part of the entrance examination) evidenced significantly higher vocabulary scores compared to students who failed the reading comprehension test.

Where academic achievement is concerned, SavilleTroike [16] found that vocabulary knowledge was a predictor of academic achievement of non-native-English-speaking children, aged 6 to 12 years old, mainstreamed in Englishmedium classes. More recently, Loewen and Ellis [17] reported similar results for ESL university students.

It appears therefore that, as far as second language learners are concerned, there is evidence to suggest that vocabulary knowledge influences both reading comprehension and academic achievement, particularly when such achievement is based on performance in courses that demand a considerable amount of writing from students. However, as noted earlier the question of whether there is a relationship between vocabulary knowledge and oral performance of second language learners has not yet been examined.

\section{METHOD}

The main purpose of this study was to find out whether there are any relationships between the English oral performance of intermediate level Japanese students learning English in New Zealand and (i) their language contact outside the classroom, and (ii) their vocabulary knowledge.

\section{Participants}

The participants were 73 students, all Japanese born and native speakers of Japanese. Twenty-two of the students were male, and 51 were female. Their ages ranged from 18 to 67 , with the mean age being 27.78 years.
The participants were all enrolled in intermediate level classes at various language schools in Auckland, New Zealand. They were recruited directly from these language schools and via advertisements that the first author placed on notice boards, websites, magazines, and newspapers.

Approval for the conduct of this study was obtained from the human participants ethics committee of the authors' university. All the participants took part in this study voluntarily. Their explicit participation consent was obtained in writing.

\section{Instruments and Procedures}

This study was part of a larger study that also examined the influence of personality and anxiety on second language learner's oral performance. However, this report deals only with the aspects relating to language contact and vocabulary. The instruments used in this part of the study were a language contact profile, and Nation's [18, 19] Vocabulary Levels Test. A story-retelling task was used to assess the participants' oral performance.

A language contact profile was developed for this study based on the profile developed by Seliger [5] and adapted by Day [11]. The language contact profile used in this study was written in the Japanese language and collected information on the number of hours the participants spent on various out-of-class activities using the English language, as well as background information relating to their study of the English language.

The Vocabulary Levels Test [19] was administered to obtain measures of the vocabulary knowledge of the participants. The test was originally developed by Nation [18] based on several published word frequency counts. Each section of the test assesses knowledge about the common meanings of words occurring at the 2000-, 3000-, 5000-, and 10000 -frequency levels. Thus, if an individual correctly answers $50 \%$ of the items on the 2000 -word level, this would indicate that he or she probably knows about 1000 - or half of the first 2000 most common words in English. The test, therefore, allows an estimation of an individual's vocabulary size: correctly answering $50 \%$ of the items on the 5000 -word level, for example, would suggest an approximate English vocabulary size of 2500 words (50\% of the 5000 most common words in English).

Each word level section of the Vocabulary Levels Test [19] is organized in sets of three definitions (e.g., 1. first, 2. not public, 3. all added together) that need to be matched with the appropriate selection from sets of six words provided (e.g., a. royal, b. slow, c. original, d. sorry, e. total, f. private). Thus, in the example given, the correct answers would be: $\mathrm{c}$ for $1, \mathrm{f}$ for 2 , and e for 3 . A maximum score of 18 is possible in each of the sections. In the present study, only the 2000-, 3000-, and 5000-word levels were used. As the participants were in intermediate level classes at their respective language schools, the 2000-, 3000-, and 5000word levels were deemed to be appropriate for their likely English language competence.

The story retelling task, administered as a gauge of the participants' oral performance, used six picture cards from the Wechsler Adult Intelligence Scale (1966 Edition) Picture Arrangement subtest. The cards used were the ones that de- 
pict a man who stops two boys from fighting over a comic book and then ends up reading the comic book himself. The participants were given the cards in a sequentially incorrect order, according to the numbers on the reverse side of the cards - following the instruction provided in this edition of the Wechsler Adult Intelligence Scale [20]. The participants were allowed approximately two minutes to organize the cards so that they were 'sequentially correct' and to make up a story with the use of all the cards.

It needs to be noted that the experimenter was not particularly concerned about the correct sequencing of the cards (according to the Scale manual) during the administration of this task. The focus was more on how the participants orally conveyed the stories they constructed. Once the participants had arranged the cards, they were asked to remember only the structure of the story they had come up with, and not to think about how to retell the story in English. The participants were asked to indicate when they were ready to retell the story and, when they did so, recording was begun using an MD (mini disk) recorder with a microphone. No time limit was given to the participants. The spoken data were transcribed as soon as practicable after collection.

The spoken data gathered from the story retelling task were analysed in terms of fluency, accuracy, complexity, and global impression. Fluency was measured by speech rate, and was calculated as the average number of syllables uttered per second. Phonetic devices were excluded when counting syllables. Another measure of fluency employed was to count the number of phonetic devices such as 'um', 'er' and 'mm' and divide the total number of these by the total speaking time. Japanese and English expressions such as 'I don't know' and 'What's the word?' were also counted as phonetic devices.

Accuracy was measured by calculating the ratio of correct clauses out of the total number of clauses used. Clauses included were: (i) co-ordinated clause (e.g., The old gentleman stopped the two boys fighting and (he) separated them.), (ii) nominal clause (e.g., He saw what they were fighting about.), (iii) relative clause (e.g., The magazine which had a picture of Atom Boy was on the ground.), (iv) adverbial clause (e.g., He took the magazine after the boys left.), (v) comparative clause (e.g., The children felt better than when they were fighting.), (vi) nonfinite clause (e.g., The man told the boys to be good.), and (vii) verbless clause (e.g., He thought it was okay to do that if unseen.) [21]. A 'correct' clause pertains to "a clause in which there is no error in syntax, morphology, or word order" (p. 310) [22]. A clause was considered correct as long as it made sense, even in cases where participants used an article incorrectly within a clause. All fillers, false starts and co-ordinating conjunctions were excluded from the count.

Another measure of accuracy employed was to divide the number of correct verbs by the total number of verbs. Verbs included were: (i) third person singular (e.g., He goes), (ii) regular past (e.g., play - played), (iii) irregular past (e.g., go - went), (vi) progressive participle 'be' auxiliary (e.g., They are fighting.), (v) perfect participle (e.g., They have finished fighting.), (vi) passive participle 'be/get' auxiliary (e.g., They were told off by the old man.), (vii) modal (e.g., He may not listen.), (viii) 'do' auxiliary (e.g., Don't fight.), (ix) copula (e.g., It looks interesting.) and (x) nonfinite forms (e.g., He wants to read it.). Where repetition occurred, all verbs including repetitions were analysed. In cases where the meaning of a verb produced was unnatural, the verb was still counted as correct if it made sense.

Complexity was measured by calculating the number of words per T-unit. T-unit, as defined by Richards, Platt, and Platt [23], is "a measure of the linguistic complexity of sentences, defined as the shortest unit (the Terminable Unit, Minimal Terminable Unit, or T-unit) which a sentence can be reduced to and consisting of one independent clause together with whatever dependent clauses are attached to it" (p. 390). Another measure of complexity employed was the mean length of the three longest utterances (MLU3), previously described and used by Dewaele \& Furnham [24]. Fillers, repetitions, reformulations, replacements and false starts that occurred were excluded from the count.

For global impression, three raters provided ratings of the global impression of the participants' oral performance using a rating scale developed for this study (see Appendix). One of the raters was the first author, and the other two were colleagues with no vested interest in the outcomes of the study. They carried out the ratings - independently of each other by listening to the participants' recorded oral performance while considering the nature of the story they made, the language resources they used, and intelligibility/confidence.

Inter-rater reliability scores for fluency, accuracy, complexity, and global impression were calculated and found to be at levels that can be considered satisfactory. These were measures of agreement between the scores/ratings provided by the first author and those provided by the same two colleagues noted above. The inter-rater reliability scores were: $100 \%$ and $94 \%$ agreement on filled pauses; $100 \%$ and $88 \%$ agreement on speech rate; $82 \%$ and $88 \%$ agreement on correct clauses; $100 \%$ and $94 \%$ agreement on correct verbs; $88 \%$ and $82 \%$ agreement on words / T-unit; $88 \%$ and $94 \%$ agreement on MLU3; and $93 \%$ and $86 \%$ agreement on global impression.

From the language contact profile administered, data was gathered about the following six variables: (i) duration of stay in English-speaking countries, (ii) duration of studying English at various institutions, (iii) amount of language contact at various places outside of language school, (iv) language contact at home with participants' interlocutors, (v) language contact with friends, and (vi) language contact in terms of tasks other than speaking. Pearson product moment correlation coefficients were calculated to examine the relationships between these and the measures taken of participants' oral performance. Participants' vocabulary scores were analysed in the same manner. Analysis of effect size was undertaken using $|r|$ (the absolute value of $r$ ) to calculate the effect size, based on Sugisawa's suggestion [25]. The effect sizes obtained were then compared with Cohen's Standard for small, medium, and large effects [26].

\section{RESULTS}

\section{Duration of Stay in English-Speaking Countries}

The mean length of time that the participants had lived in New Zealand was 6.17 months $(S D=8.86)$ and the mean length of time that they had lived in other English-speaking countries apart from New Zealand was 1.25 months $(S D=$ $3.53)$. 
Table 1. Pearson Correlations Between the Participants' Duration of Stay in English-Speaking Countries and Oral Performance Measures

\begin{tabular}{|c|c|c|c|c|}
\hline \multicolumn{2}{|c|}{ Oral Performance Measure } & $\begin{array}{c}\text { New Zealand } \\
118\end{array}$ & $\begin{array}{c}\text { Others } \\
.007\end{array}$ & $\begin{array}{c}\text { Total } \\
.110\end{array}$ \\
\hline \multirow[t]{2}{*}{ Accuracy } & Accurate Clause Rate & .061 & -.090 & .023 \\
\hline & Verb Accuracy & -.003 & -.004 & -.004 \\
\hline Complexity & Word/T-Unit & $.301 * *$ & .111 & $.307 * *$ \\
\hline Global Impression & & .042 & -.011 & .034 \\
\hline
\end{tabular}

$* * p<.01$.

Table 1 shows the correlations between the participants' duration of stay in English-speaking countries and their oral performance. While no significant correlations were found between the participants' duration of stay in other Englishspeaking countries (i.e., not including New Zealand) and the oral performance measures taken, both the participants' duration of stay in New Zealand, and their total length of stay in English-speaking countries, were found to significantly correlate with complexity in speaking performance as measured by words per T-unit. The effect sizes derived from these significant correlations both exceeded Cohen's criterion for medium size effects [26]. This finding suggests that the longer the participants had stayed in English-speaking countries - including New Zealand - the more complex their English speaking performance was.

\section{Duration of Studying English at Various Institutions}

The mean lengths of time that the participants had spent studying English at various institutions were as follows: 31.89 months in high school $(S D=11.35), 16.26$ months at university $(S D=17.49), 5.16$ months in English language schools in Japan $(S D=11.31), 2.04$ months in English language schools outside of Japan $(S D=3.52)$, and 1.52 months in miscellaneous other institutions $(S D=7.73)$. The mean total amount of time that the participants had spent studying English at various institutions amounted to 57.28 months $(S D=27.16)$.
The correlations between the participants' duration of studying English at various institutions and their oral performance are shown in Table $\mathbf{2}$ (where High = high school, Uni = university, LanJ = language school in Japan, and LanO = language school outside of Japan). The total amount of time that the participants had spent studying English at various institutions was found to significantly correlate with fluency as measured by speech rate, and with global impression. The corresponding effect sizes both exceeded Cohen's criterion for medium size effects [26]. This suggests that the longer the participants had studied English, the more fluent they were and the better global impression they made when speaking.

\section{Amount of Language Contact at Various Places Outside of Language School}

The mean amounts of time per week that the participants reported speaking English at various places outside of the language school they were attending at the time the present study was conducted were as follows: 6.03 hours at home (i.e., their 'home' in New Zealand at the time) $(S D=8.15)$, 1.32 hours at work $(S D=4.30), 0.68$ of an hour in nonEnglish language classes (e.g., sports, cultural lessons) $(S D=$ $3.61)$, and 1.81 hours at various other places $(S D=7.04)$. The mean total amount of time the participants spoke English outside of their language classes was 9.82 hours per week $(S D=11.62)$.

Table 2. Pearson Correlations Between the Participants' Duration of Studying English at Various Institutions and Oral Performance Measures

\begin{tabular}{|c|c|c|c|c|c|c|c|}
\hline \multicolumn{2}{|c|}{ Oral Performance Measure } & \multirow{2}{*}{$\begin{array}{r}\text { High } \\
.022\end{array}$} & \multirow{2}{*}{$\frac{\text { Uni }}{.181}$} & \multirow{2}{*}{$\begin{array}{r}\text { LanJ } \\
.124\end{array}$} & \multirow{2}{*}{$\begin{array}{c}\text { LanO } \\
.043\end{array}$} & \multirow{2}{*}{$\begin{array}{c}\text { Other } \\
.080\end{array}$} & \multirow{2}{*}{$\begin{array}{c}\text { Total } \\
.295^{*}\end{array}$} \\
\hline Fluency & Speech Rate & & & & & & \\
\hline \multirow[t]{2}{*}{ Accuracy } & Accurate Clause Rate & -.079 & .162 & .154 & -.006 & -.052 & .175 \\
\hline & Verb Accuracy & -.072 & .023 & -.012 & -.055 & .029 & .076 \\
\hline Complexity & Words/T-Unit & .003 & .225 & .019 & -.071 & .122 & .210 \\
\hline Global Impression & & .022 & .133 & .157 & .026 & .096 & $.243^{*}$ \\
\hline
\end{tabular}

${ }^{*} p<.05$. 
Table 3. Pearson Correlations Between the Participants' Reported Amounts of Time Speaking English at Various Places Outside of Language School and Oral Performance Measures

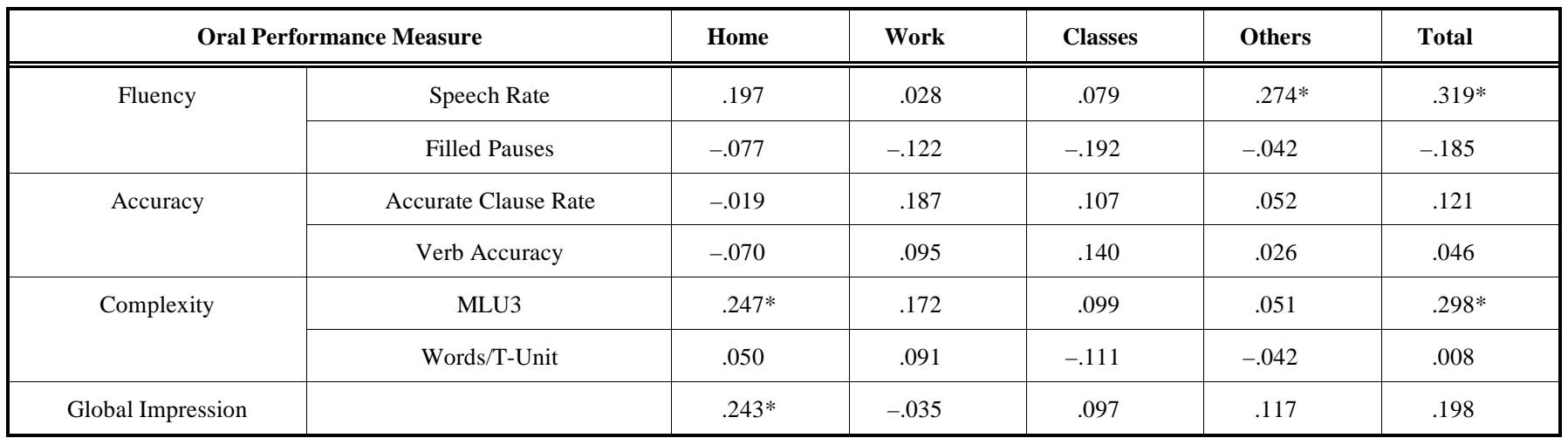

$* p<.05$.

Table 3 shows the correlations between the amounts of time the participants spent speaking English at various places outside of language school and their oral performance. Both 'Others' and 'Total' were found to correlate significantly with speech rate. This suggests that participants who spent more time speaking English at various places other than those specified - and in total - were more fluent in terms of their speech rate. The amounts of time spent on speaking English at home and in total were found to significantly correlate with complexity as measured by MLU3. This suggests that the more time the participants spent speaking English at home - and in total - the more complex their speaking performance was. Furthermore, the amount of time the participants spent speaking English at home was also found to be significantly correlated with global impression - suggesting that the benefits of speaking English at home also extends to being able to create a better impression when speaking. All effect sizes derived from these significant correlations exceeded Cohen's criterion for medium size effects [26].

\section{Language Contact at Home with Participants' Interlocu- tors}

The mean amounts of time per day that the participants reported speaking in English with their interlocutors at home were as follows: 0.79 of an hour with English native speakers (NS) $(S D=5.08), 1.27$ hours with non-native speakers of English (NNS) other than Japanese $(S D=4.01)$, and 0.37 of an hour with Japanese native speakers (JNS) $(S D=1.22)$. The mean total amount of time the participants reported speaking English with NS, NNS, and JNS interlocutors at home was 2.41 hours per day $(S D=4.26)$.

The correlations between language contact with participants' interlocutors at home and their oral performance are shown in Table 4. None of the correlations obtained here were significant.

\section{Language Contact with Friends}

The mean amount of time that the participants reported speaking English with friends who were native English speakers (FNS) was 1.88 hours per week $(S D=5.08)$, while with friends who were non-native English speakers (FNNS) the mean amount reported was 5.95 hours per week $(S D=$ 9.65). The total amount of time that the participants reported speaking with friends in general was 11.96 hours per week $(S D=36.57)$. This total includes speaking in both English and their native language, Japanese. It shows that even though the participants were living in an English speaking country, more than a third of the time they spent speaking with friends was in their native language rather than in English.

Table 5 shows correlations between language contact, as measured by amount of time the participants spent on speaking with friends, and their oral performance. A significant correlation was found between the amount of time the par-

Table 4. Pearson Correlations Between the Participants' Reported Amounts of Time Speaking English with Various Interlocutors at Home and Oral Performance Measures

\begin{tabular}{|c|c|c|c|c|c|}
\hline \multicolumn{2}{|c|}{ Oral Performance Measure } & \multirow{2}{*}{$\begin{array}{c}\text { FNS } \\
.199\end{array}$} & \multirow{2}{*}{$\begin{array}{c}\text { FNNS } \\
.117\end{array}$} & \multirow{2}{*}{$\begin{array}{c}\text { JNS } \\
-.019\end{array}$} & \multirow{2}{*}{$\begin{array}{c}\text { Total } \\
.158\end{array}$} \\
\hline Fluency & Speech Rate & & & & \\
\hline \multirow[t]{2}{*}{ Accuracy } & Accurate Clause Rate & -.050 & -.046 & .048 & -.043 \\
\hline & Verb Accuracy & -.022 & -.008 & .081 & .011 \\
\hline Complexity & Words/T-Unit & -.025 & .017 & -.096 & -.019 \\
\hline Global Impression & & .155 & .141 & .115 & .207 \\
\hline
\end{tabular}


Table 5. Pearson Correlations Between the Amounts of Time the Participants Reported they Spent Speaking with Native and NonNative English Speaker Friends and Oral Performance Measures

\begin{tabular}{|c|c|c|c|c|}
\hline \multicolumn{2}{|c|}{ Oral Performance Measure } & $\begin{array}{r}\text { FNS } \\
.185\end{array}$ & $\frac{\text { FNNS }}{.260^{*}}$ & $\begin{array}{r}\text { Total } \\
.072\end{array}$ \\
\hline \multirow[t]{2}{*}{ Accuracy } & Accurate Clause Rate & -.146 & -.041 & .104 \\
\hline & Verb Accuracy & -.054 & -.089 & .001 \\
\hline Complexity & Word/T-Unit & .185 & -.072 & .091 \\
\hline Global Impression & & .201 & .119 & -.048 \\
\hline
\end{tabular}

$* p<.05$.

ticipants reported speaking English with their friends who were non-native English speakers and their fluency as measured by speech rate. The effect size derived from this significant correlation exceeded Cohen's criterion for medium size effects [26]. This suggests that the longer the participants spent on speaking English with friends who, like themselves, were non-native English speakers the more fluent they became.

\section{Language Contact in Terms of Tasks Other than Speak- ing}

The mean amounts of time that the participants reported spending each week on non-speaking activities that used the English language were as follows: 6.51 hours on watching television/movies $(S D=5.89), 2.60$ hours on reading $(S D=$ $3.71), 7.06$ hours on listening to English music/radio broadcasts $(S D=9.64)$, and 1.66 hours on writing $(S D=2.05)$. The mean total time spent on these activities per week was 17.83 hours $(S D=12.92)$.

Table 6 shows the correlations between the amount of time spent on these activities and the participants' oral performance. As shown, a significant negative correlation was found between watching television/movies and verb accuracy, suggesting the more time the participants spent on watching television and/or movies the less accurate their verb usage became. In contrast, time spent on reading was found to be significantly positively correlated with speech rate and both measures of complexity. This suggests that time spent on reading is beneficial towards both fluency (in terms of speech rate) and complexity of speaking performance. All corresponding effect sizes exceeded Cohen's criterion for medium size effects [26].

\section{Vocabulary Knowledge}

Out of a maximum possible score of 18 , the participants' mean scores on each of the three levels of the vocabulary test administered were as follows: $14.41(S D=2.84)$ for the 2000 word level, $13.26(S D=3.72)$ for the 3000 word level, and $9.63(S D=3.59)$ for the 5000 word level. The mean total score for all three levels combined was $37.30(S D=9.02)$ out of a maximum possible score of 54 .

Table 7 shows the correlations between the participants' vocabulary scores and their oral performance. Where fluency was concerned, significant correlations were found between scores on all three words levels of the vocabulary test, as well as the total score, and speech rate. Here, the effect size derived from the correlation at the 5000-word level exceeded Cohen's criterion for medium size effects [26], while the other three effect sizes obtained exceeded the criterion for large size effects. However, no significant correlations were found with fluency as measured by filled pauses. Where accuracy was concerned, the vocabulary scores at both the 3000 and the 5000 word levels, as well as the total score,

Table 6. Pearson Correlations Between the Participants' Reported Amounts of Time Spent on other Activities Using English and Oral Performance Measures

\begin{tabular}{|c|c|c|c|c|c|c|}
\hline \multicolumn{2}{|c|}{ Oral Performance Measure } & Watching & Reading & Listening & Writing & Total \\
\hline \hline \multirow{2}{*}{ Fluency } & Speech Rate & .227 & $.256^{*}$ & .044 & .098 \\
\cline { 2 - 7 } & Filled Pauses & .011 & -.010 & .050 & .070 \\
\hline \multirow{2}{*}{ Accuracy } & Accurate Clause Rate & -.151 & -.163 & .021 & .040 & -.093 \\
\cline { 2 - 7 } & Verb Accuracy & $-.272^{*}$ & -.088 & -.006 & .058 & .100 \\
\hline \multirow{2}{*}{ Complexity } & MLU3 & .024 & $.261^{*}$ & .159 & .221 \\
\cline { 2 - 7 } & Words/T-Unit & .152 & $.328^{* *}$ & -.002 & .085 \\
\hline Global Impression & & .181 & .058 & -.070 & -.012 \\
\hline
\end{tabular}

$* p<.05 . * * p<.01$ 
Table 7. Pearson Correlations Between the Participants' Vocabulary Test Scores and Oral Performance Measures

\begin{tabular}{|c|c|c|c|c|c|}
\hline \multicolumn{2}{|c|}{ Oral Performance Measure } & \multirow{2}{*}{$\frac{\mathbf{2 0 0 0}}{.403^{* *}}$} & \multirow{2}{*}{$\frac{\mathbf{3 0 0 0}}{.381^{* *}}$} & \multirow{2}{*}{$\frac{\mathbf{5 0 0 0}}{.323^{* *}}$} & \multirow{2}{*}{$\begin{array}{l}\text { Total } \\
.412^{* *}\end{array}$} \\
\hline Fluency & Speech Rate & & & & \\
\hline \multirow[t]{2}{*}{ Accuracy } & Accurate Clause Rate & .194 & $.439 * *$ & $.388 * *$ & $.396^{* *}$ \\
\hline & Verb Accuracy & .125 & .392 & $.282^{*}$ & $.313 * *$ \\
\hline Complexity & Words/T-Unit & $.315^{* *}$ & $.471^{* *}$ & $.311^{* *}$ & $.417 * *$ \\
\hline Global Impression & & $.281 *$ & $.402 * *$ & $.294 *$ & $.371 * *$ \\
\hline
\end{tabular}

$* p<.05 . * * p<.01$.

were significantly correlated with both accurate clause rate and verb accuracy (with the effect sizes derived from the accurate clause rate correlations exceeding the criterion for large size effects, and those from the verb accuracy correlations exceeding the criterion for medium size effects). The scores on all three word levels and the total score were found to significantly correlate with both measures of complexity as well as with global impression, the only exception being the score on the 5000 word level where MLU3 was concerned. Effect sizes derived from the words per T-unit and global impression correlations at the 3000-word level and in total exceeded Cohen's criterion for large size effects [26], while the rest exceeded the criterion for medium size effects. These findings suggest that better vocabulary knowledge produces better oral performance as far as being more fluent, more accurate, more complex, and creating a better global impression are concerned.

\section{DISCUSSION}

The findings of this study provide some evidence to support commonly held notions about the importance of practice in language learning in general and in developing speaking skills in particular $[6,7,8]$. More specifically, the relationships found between the participants' reports about various forms of language contact and the oral performance measures taken suggest that the speaking practice gained during many of these language contact situations is beneficial towards improving speaking performance. Evidence was also found suggesting that better vocabulary knowledge produces better oral performance in terms of all the aspects examined - fluency, accuracy, complexity, and global impression. This adds oral performance to the list of areas in second language learning that appear to be influenced by vocabulary knowledge, which as noted earlier includes both reading comprehension $[14,15]$ and academic performance $[16,17]$. The following sections discuss these findings further, exploring some of the possible reasons for the relationships found (as well as those not found) in this study, and the implications of the findings towards more effective second language learning and instruction.

\section{The Usefulness of Language Contact: Getting Speaking Practice}

Perhaps not surprisingly, a relationship was found between the participants' duration of stay in English speaking countries and the complexity of their oral performance (as measured by words per T-unit). This finding lends some support to arguments about the value of studying a second language abroad - in a country where that language is spoken - that other authors have previously noted [13, 27].

However, in the present study, the relationship with complexity was found only where the participants' duration of stay in New Zealand and in total were concerned - but not with their duration of stay in other countries. This may have been due to the fact that a relatively small proportion of the participants had spent much time in other English speaking countries prior to coming to New Zealand and, most of those who had, reportedly travelled to those other countries only for short periods of time on holiday (often in the company of other Japanese). In contrast, all of the participants were in New Zealand to study English and, although they would have had other Japanese in their classes, they were likely to have been fewer in comparison to students coming from other countries like China and Korea. Furthermore, unlike Freed et al.'s [12] and Wilkinson's [28] reports of American students living and studying in France but using more English in out-of-class contact than French, the Japanese students in the present study would have quickly found that they needed to use English as (i) there are very few Japanese in the general population in New Zealand, and (ii) the rest of the population - with very few exceptions - can neither understand nor speak Japanese. Thus, for most Japanese students, studying English in New Zealand - or any other English speaking country where relatively few Japanese live and where most in the population do not know the Japanese language - would likely equate to having to use English in many everyday situations.

This likely need to use the second language (in this case English) in many everyday situations may explain the significant correlation found with complexity in particular. Effective oral communication in many everyday situations basically requires the ability to string together phrases and/or sentences that will be understood: the more complex the situation encountered and the message that needs to be conveyed (e.g., seeking a replacement or refund for a faulty product, as opposed to simply purchasing something), the more complex those phrases and/or sentences will need to be. Staying longer in another country will inevitably increase the need to deal with and communicate about more complex situations. In such situations - where the need to be under- 
stood is of utmost importance - fluency, accuracy, and the global impression made when speaking may not be as crucial.

The accumulated benefits of studying the second language on the ability to speak the language is highlighted by the finding that the participants' total duration of studying English was related to both speech rate (one of the measures of fluency used) and global impression. However, where English was studied did not appear to matter in this case as no links were found between the duration of study at any of the locations specified and the oral performance measures taken. This suggests that it is the length of time devoted to studying the second language that matters as far as fluency and being able to create a better impression when speaking are concerned.

Possible reasons why no links were found between the duration of studying English and the oral performance measures of accuracy and complexity need to be considered. One possible explanation is that speaking accuracy and complexity may not be as salient in the classroom situation as fluency (being able to speak more within a given amount of time) and global impression (being able to make a good impression during one's speaking performance). This leads to two further possibilities: first, that students themselves may pay more attention to developing their speaking fluency and ability to create a good impression so they would not "look or feel bad" when called upon to speak in class; and secondly, that second language instruction - as far as speaking performance is concerned - may not adequately focus on the accuracy and complexity aspects, as compared to the more salient fluency and global impression aspects. Both of these warrant further investigation.

Again, it was perhaps not surprising to find that the total amount of time the participants spent speaking English at various places outside of language school appeared to have a positive influence on both fluency (as measured by speech rate) and complexity (as measured by MLU3). Using English in 'other' places (apart from home, work, and other classes, and include, e.g., social occasions such as in cafes, friends' house, etc.) also appeared to have a positive influence on speech rate. These places outside of the classroom are likely to present second language students, like the participants of the present study, with opportunities to practice speaking the second language more - hence cultivating fluency. Most of these places outside of the classroom are also likely to present challenges for more complex communication, as noted earlier where duration of time spent in English speaking countries was concerned. However, while speaking English with friends in informal situations (like in the 'other' location category) is likely to enhance fluency, it may not present as many challenging situations for more complex oral communication - making the lack of significant correlation with complexity here quite understandable.

The reported amounts of time the participants spent using English in the home also appeared to improve complexity and global impression. However, none of the amounts of time the participants reported they spent speaking English with various interlocutors at home proved significantly correlated with any of the measures of oral performance used. This suggests that who the participants spoke English with was not the crucial issue. Rather, what seems important was that they got English language contact outside of the classroom, giving them the necessary additional practice in actually speaking English.

The value of actually getting speaking practice in the second language - irrespective of who with - is further highlighted by the finding that the amount of time the participants spent speaking with friends who were non-native speakers of English (FNNS) was significantly correlated with speech rate. The time spent speaking with friends who were native speakers of English (FNS), on the other had, did not significantly correlate with any of the oral performance measures used. A possible explanation for this is that with FNS the participants may not have got as much practice in actually speaking English despite the contact time spent with them. Reasons could include FNS simply doing most of the talking and lack of confidence when speaking with FNS. Schmidt-Rinehart and Knight [29], for example, reported that some of the American students in homestay situations in Spain and Mexico complained that the "senora" (i.e., their host mother) spoke so much that they did not get much opportunity to practice speaking Spanish at home. Ingram [27] also described how American college students in a study abroad program in France found it much less intimidating to speak to French high school students who were younger than them. Likewise, the participants in the present study may have found it less intimidating to speak English with FNNS (compared to FNS) and hence got more practice in actually speaking English with them.

The importance of actually speaking to improve speaking performance in the second language is further highlighted by the finding that the amounts of time the participants reported to have spent outside of class on listening and writing in English did not correlate with any of the oral performance measures taken. Positive correlations (with speech rate and the complexity measures) were found only with the reported amounts of time spent on reading in English outside of class. This may have been due to reading practice providing more opportunities to reflect on and learn not only new words (see discussion about vocabulary in the next section) but also better and more complex sentence construction in English. Such opportunities may be considerably less as far as the more passive activity of listening is concerned, and the participants may have spent far too little time on writing in English outside of class (less than 2 hours per week) for this to have made any difference to their oral performance (cf. Freed et al.'s finding of out-of-class writing activities in French being related to gains in speech rate [12]).

The finding that the amount of time the participants spent on watching television and movies was negatively correlated with verb accuracy lends support to the notion that not all forms of language contact are beneficial. Although there seems to be little or no research on the effects of television watching on the language competencies of second language learners, elsewhere (i.e., with students operating in their native language) watching television has been linked to negative outcomes in some scholastic activities such as studying and reading (see reviews by Hornik [30], Ritchie, Price, \& Robert [31]). The poorer verb accuracy linked to time spent on watching television and movies may have been due to this activity not only being passive and providing little or no opportunities for English speaking practice, but also to it taking 
time away that the participants could have otherwise spent on English language study.

\section{The Usefulness of Vocabulary Knowledge: Having the Words to Say}

Since knowing the words to use must be one of the factors that determine the fluency with which one is able to speak, it is not surprising to find that speech rate was correlated with vocabulary knowledge scores at all the levels examined as well as in total. A more pertinent question may be why filled pauses, the other measure of fluency used, proved unrelated to vocabulary knowledge. In fact, in this study, filled pauses did not significantly correlate with any of the factors examined, including those relating to language contact. And looking at previous studies on second language oral performance that have employed filled pauses as a measure of fluency [32, 33] reveals that this measure has also failed to show correlations with assessments of personality and anxiety. It may therefore simply be the case that filled pauses is not a useful measure of speaking fluency. The use of filled pauses when speaking (e.g., "um", "er", "mm") may be considerably influenced by acquired speaking styles and habits to dependably portray the speaking competence of second language learners.

Vocabulary test scores at the higher levels and in total were found to be significantly correlated with the measures of oral performance accuracy employed, suggesting that more advanced levels of vocabulary knowledge contribute to both clause and verb accuracy when speaking. Considering what more advanced vocabulary knowledge might entail (e.g., knowing more words and their variations) and be associated with (e.g., better understanding of the grammar that applies to the use of the known words), its possible contribution to the ability to utter more accurate clauses and verbs is understandable. In contrast, vocabulary knowledge at the lower levels may be too basic and focused simply on the correspondence between words and their meanings to make any significant contribution to these aspects of speaking accuracy.

The significant correlations found between vocabulary test scores and the measures of oral performance complexity used suggest that knowing more words enables the construction of more complex sentences and phrases when speaking. This makes sense especially as both measures of complexity
- MLU3 and words per T-unit - actually depend on the number of words used. Knowing more words would likely enable the use of more words when speaking.

Possible explanations for the relationship found between vocabulary knowledge and global impression created by the participants during their oral performance become apparent when the qualities included in the global impression marking scheme (detailed in the Appendix) are considered. Better vocabulary knowledge and having more words at one's disposal is likely to facilitate the ability to tell a story better, to demonstrate a more extensive range of language resources (which includes vocabulary), and to come across more intelligibly. Better vocabulary knowledge could also contribute to boosting the speaker's confidence, which would come across when speaking and influence the overall impression created.

\section{CONCLUSION}

The present authors acknowledge that causality cannot be assumed between the language contact and vocabulary measures used in this study and the aspects of oral performance they were found to correlate with. It would therefore be useful to take a more experimental approach in future studies to confirm whether learning and instruction strategies based on these findings do produce the desired gains in the oral performance of second language learners.

Table 8 summarizes the findings of this study and depicts the different aspects of oral performance that vocabulary knowledge and the language contact factors examined in this study seem to benefit. The implications for second language teaching and learning appear quite clear: that to improve speaking performance, vocabulary development and getting plenty of actual speaking practice are paramount. These should therefore be promoted much more actively in the classroom setting if more effective development of students' oral performance skills is desired. Placing greater emphasis on speaking practice would be congruent with classroom conduct advocated in communicative approaches to second language teaching (see, e.g., Krashen \& Terrell [34], Littlewood [35], Savignon [36]). Vocabulary teaching is an integral part of virtually all second language teaching approaches but perhaps, in light of the findings of this study, teachers ought to more actively facilitate the development of students' appreciation of the connection between newly acquired vocabulary words and their increasing ability to ver-

Table 8. Vocabulary Knowledge and Language Contact Factors, and the Aspects of Oral Performance they Appear to Positively Influence

\begin{tabular}{|c|c|c|c|c|}
\hline \multirow{2}{*}{ Factors } & \multicolumn{4}{|c|}{ Oral Performance Measures } \\
\cline { 2 - 5 } & Fluency & Accuracy & Complexity & Global Impression \\
\hline \hline Vocabulary Knowledge & $\sqrt{ }$ & $\sqrt{ }$ & $\sqrt{ }$ \\
\hline Living in English Speaking Countries & & & $\sqrt{ }$ \\
\hline Duration of Studying English & $\sqrt{ }$ & & $\sqrt{ }$ \\
\hline Speaking English Outside of Class & $\sqrt{ }$ & & $\sqrt{ }$ \\
\hline Speaking English with Friends & $\sqrt{ }$ & & $\sqrt{ }$ \\
\hline Reading & $\sqrt{ }$ & & \\
\hline
\end{tabular}




\section{APPENDIX}

Rating Scales for Global Impression Marking Scheme

\begin{tabular}{|c|c|}
\hline Band & Description \\
\hline $\begin{array}{l}\text { 4. Advanced level of oral profi- } \\
\text { ciency }\end{array}$ & $\begin{array}{l}\text { Nature of Story: Story well told; able to elaborate. } \\
\text { Language Resources: Good range of language resources (vocabulary, grammar, linkage), including low frequency } \\
\text { words. } \\
\text { Intelligibility / Confidence: Confident speaker. Successful communicator. }\end{array}$ \\
\hline 3. Average oral proficiency & $\begin{array}{l}\text { Nature of Story: Story is not so elaborate as Band } 4 \text { but storyline is apparent. } \\
\text { Language Resources: Limited language resources (vocabulary, grammar, linkage). Mostly uses common words. Uses } \\
\text { some links (so, and then, etc.). } \\
\text { Intelligibility / Confidence: Always intelligible. Reasonably confident delivery. }\end{array}$ \\
\hline $\begin{array}{l}\text { 2. Just below average oral profi- } \\
\text { ciency }\end{array}$ & $\begin{array}{l}\text { Nature of Story: Story is not clear and sometimes causes strain. } \\
\text { Language Resources: Lacks language resources (vocabulary, grammar, linkage). No explicit links between sentences. } \\
\text { Intelligibility / Confidence: Sometimes unintelligible. Unconfident delivery. }\end{array}$ \\
\hline $\begin{array}{l}\text { 1. Elementary level of oral profi- } \\
\text { ciency }\end{array}$ & $\begin{array}{l}\text { Nature of Story: Unable to tell the story. } \\
\text { Language Resources: Very basic language resources (vocabulary, grammar, linkage). Difficulties making sentences. } \\
\text { Intelligibility / Confidence: Often unintelligible. Poor communicator. }\end{array}$ \\
\hline
\end{tabular}

bally communicate in the second language in question. There are many classroom exercises that would achieve this, including explicitly requiring students to use the newly acquired words in meaningful contexts in conversational practice sessions in class.

The summary of findings depicted in Table $\mathbf{8}$ also suggests that persistence in studying the second language (in this case, English) can be expected to pay off, and that programs providing opportunities to live in countries where the second language is spoken can help develop speaking complexity. These suggestions from the findings need not be viewed as independent of each other: strategies could be devised that would facilitate both. For example, in situations where developing students' English speaking abilities is imperative, the provision of performance-based financial grants to support opportunities to travel to and study in English speaking countries would likely promote greater effort and persistence amongst the target group of students. Finally, as Table 8 shows, the summary of findings suggests that reading - although an activity that does not provide actual speaking practice - should be encouraged as it can contribute to the development of both fluency and complexity in speaking.

\section{ACKNOWLEDGEMENTS}

The authors would like to thank Cathie Elder, Karin Farreyrol, Penny Hacker, Tania Huddart, Erik Landhuis, Shawn Loewen, Paul Sutcliff, Julie Trafford, Josta van RijHeyligers, and David Welch for their help and advice.

\section{REFERENCES}

[1] Kitao SK, Kitao K, Nozawa K, Yamamoto M. Teaching English in Japan [Online]. [Cited 2008 Oct 16]. Available from: http://www1.doshisha.ac.jp/ kkitao/library/article/tejk.htm

[2] Institute of International Education. Open doors 2005: Leading places of origin [Online]. New York: Institute of International Education; c2004-2008 [cited 2008 Oct 17]. Available from: http://opendoors.iienetwork.org/?p=69691
[3] Read J. Assessing vocabulary. Cambridge: Cambridge University Press 2000.

[4] Levelt WJM. Speaking: From intention to articulation. Cambridge, MA: MIT Press 1989.

[5] Seliger HW. Does practise make perfect? A study of interaction patterns and L2 competence. Lang Learn 1977; 27: 263-78.

[6] d'Anglejan A. Language learning in and out of classrooms. In: Richards JC, Ed. Understanding second and foreign language learning: Issues \& approaches. Rowley, Mass: Newbury House 1978. pp. 218-36.

[7] Harley B, Allen P, Cummins J, Swain M, Eds. The development of second language proficiency. Cambridge: Cambridge University Press 1990.

[8] Harley B, Swain, M. An analysis of the verb system by young learners of French. Interlang Stud Bull 1978; 3: 35-79.

[9] Constantino R. Pleasure reading helps, even if readers don't believe it. J Read 1994; 37: 504-05.

[10] Constantino R. Learning to read in a second language doesn't have to hurt: The effect of pleasure reading. J Adolesc Adult Lit 1995; 39: 68-69.

[11] Day RR. Student participation in the ESL classroom or some imperfections in practice. Lang Learn 1984; 34: 69-102.

[12] Freed BF, Segalowitz N, Dewey DP. Context of learning and second language fluency in French: Comparing regular classroom, study abroad, and intensive domestic immersion programs. Stud Second Lang Acquis 2004; 26: 275-301.

[13] Segalowitz N, Freed BF. Context, contact, and cognition in oral fluency acquisition: Learning Spanish at home and study abroad contexts. Stud Second Lang Acquis 2004; 26: 173-99.

[14] Laufer B. A factor of difficulty in vocabulary learning: Deceptive transparency. AILA Rev 1989; 6: 10-20.

[15] Hazenberg S, Hulstijn J. Defining a minimal receptive secondlanguage vocabulary for non-native university students: An empirical investigation. Appl Linguist 1996; 17: 145-63.

[16] Saville-Troike M. What really matters in second language learning for academic achievement? TESOL Q 1984; 17: 199-219.

[17] Loewen S, Ellis R. Second language vocabulary and academic achievement in undergraduate university students. In: Manalo E, Wong-Toi G, Eds. Communication skills in university education: The international dimension. Auckland, New Zealand: Pearson Education 2005. p. 260-76.

[18] Nation ISP. Testing and teaching vocabulary. Guidelines 1983; 5(1): $12-25$.

[19] Nation ISP. Teaching and learning vocabulary. Boston: Heinle and Heinle 1990. 
[20] Australian Council for Educational Research. Wechsler Adult Intelligence Scale. Victoria, Australia: Australian Council for Educational Research 1966

[21] Kennedy G. A pedagogical description of English: A corpus-based guide to structures and meanings for teachers of English. Wellington, New Zealand: Victoria University of Wellington 2000.

[22] Foster P, Skehan P. The influence of planning on performance in task-based learning. Stud Second Lang Acquis 1996; 18: 299-324.

[23] Richards J, Platt J, Platt H. Longman dictionary of language teaching and applied linguistics. Essex: Longman 1992.

[24] Dewaele J-M, Furnham A. Personality and speech production: A pilot study of second language learners. Personality and Individual Differences 2000; 28: 355-65.

[25] Sugisawa T. Statistical power of educational psychology research in Japan. Japanese J Educ Psychol 1999; 47: 150-59.

[26] Cohen J. Statistical power analysis for the behavioral sciences. 2nd ed. Hillsdale, NJ: Lawrence Earlbaum Associates 1988.

[27] Ingram $M$. Recasting the foreign language requirement through study abroad: A cultural immersion program in Avignon. Foreign Lang Annals 2005; 38: 211-22.

[28] Wilkinson S. Study abroad from the participants' perspectives: A challenge to common beliefs. Foreign Language Annals 1998; 31: 23-39.
[29] Schmidt-Rinehart BC, Knight SM. The homestay component of study abroad: Three perspectives. Foreign Lang Annals 2004; 37: 254-62.

[30] Hornik R. Out-of-school television and schooling: Hypotheses and methods. Rev Educ Res 1981; 51: 193-214.

[31] Ritchie D, Price V, Roberts DF. Reading and television: A reappraisal. Commun Res 1987; 14: 292-315.

[32] Dewaele J-M. Les phénomènes d'hésitation dans L'interlangue française: Analyse de la variation interstylistique et interindividuelle [Hesitation phenomena in French interlanguage: An analysis of interstylistic and interindividual variation]. Rassegna Italiana da Linguistica Applicata 1996; 28(1): 87-103.

[33] Oya T, Manalo E, Greenwood J. The influence of personality and anxiety on the oral performance of Japanese speakers of English. Appl Cogn Psychol 2004; 18: 841-55.

[34] Krashen S, Terrell T. The natural approach: Language acquisition in the classroom. New York: Prentice Hall 1988.

[35] Littlewood W. Communicative language teaching: An introduction. Cambridge: Cambridge University Press 1981.

[36] Savignon SJ. Communicative language teaching: State of the art. TESOL Q 1991; 25(2): 261-77.

(c) Oya et al.; Licensee Bentham Open.

This is an open access article licensed under the terms of the Creative Commons Attribution Non-Commercial License (http://creativecommons.org/licenses/by-nc/3.0/) which permits unrestricted, non-commercial use, distribution and reproduction in any medium, provided the work is properly cited. 